\title{
Deep Temporal Vein
}

National Cancer Institute

\section{Source}

National Cancer Institute. Deep Temporal Vein. NCI Thesaurus. Code C52699.

The blood vessels at the vertex and on either side of the head that drain deoxygenated blood into the pterygoid venous plexus. 